\title{
ANALISIS PERFORMA SPRAY KONDENSOR TIPE DIRECT CONTACT UNIT 3 PADA PEMBANGKIT LISTRIK TENAGA PANAS BUMI PT.X
}

\author{
*Edwin Syahrial ${ }^{1}$, Anggananda Berlian ${ }^{2}$ \\ 1,2 Fakultas Teknik dan Informatika, Program Studi Teknik Mesin, Universitas Dian Nusantara, Jakarta, Indonesia \\ *Email Korespondensi: \\ Edwin.syahrial@undira.ac.id
}

\section{ARTIKEL INFORMASI}

Diterima:

3 March 2021

Direvisi:

15 April 2021

Dipublikasi:

16 Mei 2021

\begin{abstract}
ABSTRAK
Kondensor berfungsi untuk megkondensasikan uap bekas yang digunakan untuk memutar turbin. Kondensor yang digunakan merupakan kondensor dengan jenis kontak langsung (Direct Contact Condenser). Penelitian yang dilakukan adalah analisis terhadap performance kondenseor. Dalam data spesifikasi dilakukan perhitungan Heat Rate pada turbin yang mempunyai hasil sebesar $20.973,036 \mathrm{~kJ} / \mathrm{kWh}$ dan untuk data aktual sebesar $20.088,783 \mathrm{~kJ} / \mathrm{kWh}$, jika di deviasikan sebesar 4,2\%. Pada perhitungan efisiensi kondensor pada data spesifikasi sebesar 89,75\% namun untuk data aktual 82,35\%. Dan Kesetimbangan energi pada kondensor desain 0,02721, sedangkan aktual 0,02505. Dari hasil analisis ini maka didapat kesimpulan pada perhitungan Heat Rate ini melebihi batas nilai toleransi dari ASME PTC 6 sebesar 2\%. Yang di sebabkannya nilai performa pada kondensor menurun yaitu tekanan pada kondensor memiliki perbedaan tekanan yang hampir banyak, sebesar 0,08 - 0,09 bar mempengaruhi kualitas steam yang masuk. Di karenakan tekanan pada kondensor sangat tergantung pada debit dan air pendingin dan isolasi dari peralatan tersebut. Tentunya hal ini akan berakibat naiknya pula perbedaan entalpi antara kondensor dengan turbin.
\end{abstract}

Keyword: Condenser, Spray condenser, PLTP

\section{PENDAHULUAN}

Indonesia merupakan salah satu negara yang berpotensi untuk menghasilkan listrik tenaga panas bumi dikarenakan Indonesia memiliki beberapa gunung berapi yang memiliki potensi untuk dikelola sebagai pembangkit panas bumi. Kondensor sebagai salah satu sistem pendingin yang sangat penting dalam sebuah sistem pembangkit energi listrik. Fungsi utama kondensor adalah untuk mengkondensasikan uap exhaust turbin, supaya menciptakan tekanan pada turbin menjadi vaccum, sehingga efisiensi siklus power plant akan naik.

Kondensor yang digunakan pada Pembangkit Listrik Tenaga Panas Bumi (PLTP) pada PT. X sebagaimana alat penukar kalor, yaitu Spray Condenser type Direct Contact Unit 3. Dimana fluida pendingin berupa air dan sedangkan fluida kerja sistem (fluida yang di dinginkan) yaitu uap exhaust turbin tekanan rendah. Meningkatnya suhu air dingin di sistem ini akan mempengaruhi jalannya kondensasi pada kondensor 
dan di ikutinya kenaikan nilai tekanan pada kondensor yang berpengaruh terhadap vaccum kondensor, sehingga kurang maksimalnya unjuk kerja dari suatu peralatan pada pembangkit itu sendiri.

Adapun identifikasi masalah pada penelitian ini adalah meningkatnya suhu air dingin di sistem ini akan mempengaruhi jalannya kondensasi pada kondensor dan di ikutinya kenaikan nilai tekanan pada kondensor yang berpengaruh terhadap vaccum kondensor, sehingga kurang maksimalnya unjuk kerja dari suatu peralatan pada pembangkit itu sendiri. Tujuan dilakukannya penelitian ini adalah mendapatkan kondisi perfoma kondensor pada temperatur dan tekanan kondensor sehingga meningkatkan produktifitas dari kinerja turbin.

\section{KAJIAN PUSTAKA}

\section{Tinjauan Umum PLTP}

Pembangkit listrik tenaga panas bumi adalah pembangkit listrik yang menggunakan panas bumi (geothermal) sebagai energi penggeraknya. Indonesia dikaruniai sumber panas bumi yang berlimpah karena banyaknya gunung berapi dari pulau-pulau besar yang ada, hanya pulau Kalimantan saja yang tidak mempunyai potensi panas bumi (Carin, 2011). Keuntungan teknologi ini antara lain, bersih, dapat beroperasi pada suhu yang lebih rendah dari pada PLTN, dan aman, bahkan geothermal adalah yang terbersih dibandingkan dengan nuklir, minyak bumi dan batu bara.

Pada umumnya pembangkit listrik panas bumi berdasarkan jenis fluida kerja panas bumi yang diperoleh dibagi menjadi 3, yaitu :

a. Vapor dominated system (sistem dominasi uap)

b. Flushed steam system

c. Binary cycle system (sistem siklus biner)

Proses dalam pembangkit dimulai dari uap yang diambil dari panas bumi yang digunakan untuk memutar turbin. Jika uap tersebut bertemperatur diatas $370{ }^{\circ} \mathrm{C}$, maka PLTP menggunakan vapor dominated system dimana uap dari panas bumi langsun 4 gunakan utuk memutar turbin. Jika bertemperatur sekitar $170{ }^{\circ} \mathrm{C}$ sampai dengan $370{ }^{\circ} \mathrm{C}$, maka mengghuanan flushed steam system dimana uap masih mengandung cairan dan harus dipisahkan dengan flush separator sebelum memutar turbin. Dalam binary-cycle system uap panas bumi digunakan untuk memanaskan gas dalam heat exchanger, kemudian gas ini yang akan memutar turbin (Kevin, 2007).

\section{Prinsip Kerja PLTP}

Pembangkit Listrik Tenaga Panasbumi (PLTP) pada prinsipnya sama seperti Pembangkit Listrik Tenaga Uap (PLTU), hanya pada PLTU uap dibuat di permukaan menggunakan boiler, sedangkan pada PLTP uap berasal dari reservoir panasbumi. Apabila fluida di kepala sumur berupa fasa uap, maka uap tersebutdapat dialirkan langsung ke turbin, dan kemudian turbin akan mengubah energi panas bumi menjadi energi gerak yang akan memutar generator sehingga dihasilkan energi listrik.

Apabila fluida panasbumi keluar dari kepala sumur sebagai campuran fluida dua fasa (fasa uap dan fasa cair) maka terlebih dahulu dilakukan proses pemisahan pada fluida. Hal ini dimungkinkan denganmelewatkanfluida ke dalam separator, sehingga fasa uap akan terpisahkan dari fasa cairnya. Fraksi uap yang dihasilkan dari separator inilah yang kemudian dialirkan ke turbin.

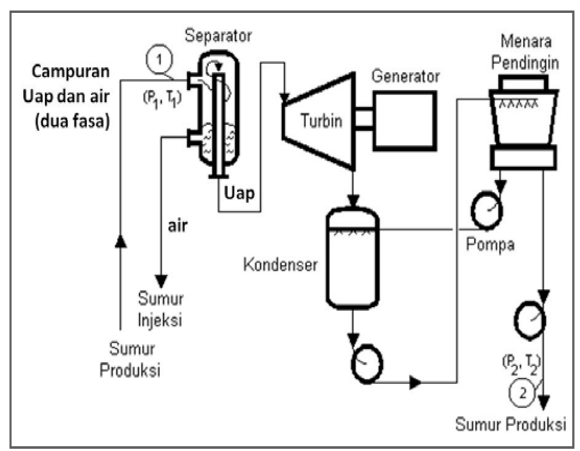

Gambar 1. Flow Diagram PLTP

Apabila sumber daya panasbumi mempunyai temperatur sedang, fluida panasbumi masih dapat dimanfaatkan untuk pembangkit listrik dengan menggunakan pembangkit listrik siklus binari (binary plant). Dalam 
siklus pembangkit ini, fluida sekunder (isobutane, isopentane or ammonia) dipanasi oleh fluida panasbumi melalui mesin penukarkalor atau heat exchanger. Fluida sekunder menguap pada temperatur lebih rendah dari temperatur titik didih air pada tekanan yang sama. Fluida sekunder mengalir ke turbin dan setelah dimanfaatkan dikondensasikan sebelum dipanaskan kembali oleh fluida panas bumi. Siklus tertutup dimana fluida panas bumi tidak diambil masanya, tetapi hanya panasnya saja yang diekstraksi oleh fluida kedua, sementara fluida panas bumi diinjeksikan kembali kedalam reservoir. Prinsip kerja tersebut merupakan kerja dari sistim yang terpasang pada komponen-komponen antara lain Separator, Demister, Turbin, Kondensor, Main cooling water pump (MCWP), dan Cooling Tower.

\section{Spray Condenser}

Kondensor berfungsi untuk megkondensasikan uap bekas yang digunakan untuk memutar turbin. Kondensor yang digunakan merupakan kondensor dengan jenis kontak langsung (Direct Contact Condenser), dimana air yang berasal dari cooling tower atau media kondensasi langsung di semprotkan melalui spray nozzle yang kemudian akan berkontak langsung dengan uap bekas memutar turbin. Uap akan terkondensasi dan dikeluarkan kondensor bersama-sama dengan media kondensasinya. Uap atau gas yang tidak dapat terkondensasi akan dihisap oleh ejector yang mana uap tersebut disebut dengan Non Condensable Gas (NCG). NCG ini biasanya mengandung $85-90 \%$ wt $\mathrm{CO}_{2}, 3 \%$ wt $\mathrm{H}_{2} \mathrm{~S}$, dan sisanya adalah $\mathrm{N}_{2}$ dan gas lainnya.

\section{Parameter Performa Kondensor \\ Heat Rate pada Turbin}

Turbine heat rate dapat dihitung dengan persamaan (ASME PTC 6)

$$
\begin{aligned}
& T S R=\frac{m\left(\frac{k g}{h}\right)}{W(k W)} \\
& T H R=T S R \times h\left(\frac{k J}{k g}\right)
\end{aligned}
$$

Dimana:

TSR : Turbine Steam Rate

$\mathrm{m}:$ Main steam flow $(\mathrm{kg} / \mathrm{h})$

$\mathrm{W}$ : Daya output $(\mathrm{kWh})$

$\mathrm{h}$ : Entalpi output $(\mathrm{kJ} / \mathrm{kg})$

\section{Efisiensi Kondensor}

Metode output - input

$$
\eta_{\text {cond }}=\frac{H 2}{H 1+H 3} \times 100 \%
$$

\section{Kesetimbangan Energi Kondisi Steady}

$$
\text { Ws. } h 1+\text { Wct. } h 2=\text { Wcond } . h 3
$$

Dimana:

Ws: Laju aliran uap keluar turbin $(\mathrm{kg} / \mathrm{h})$

Wc : Laju aliran air pendingin $(\mathrm{kg} / \mathrm{h})$

Wcond : aliran condensate $(\mathrm{kg} / \mathrm{h})$

$\mathrm{H} \quad$ : Entalphy $(\mathrm{kJ} / \mathrm{kg})$

\section{Kondisi Aktual}

Dimana

$$
\mathrm{m}_{2} \cdot \mathrm{h}_{2}+\mathrm{m}_{5} \cdot \mathrm{h}_{5}=\mathrm{m}_{3} \cdot \mathrm{h}_{3}
$$

$\mathrm{m}$

h : Entalpi kJ/kg

: laju aliran massa $\mathrm{kg} / \mathrm{h}$

\section{METODE}


Metodologi penelitian merupakan tahap-tahap penelitian yang harus ditetapkan dahulu sebelum melakukan pemecahan masalah, sehingga penelitian dapat dilakukan dengan terarah dan memudahkan dalam menganalisis permasalahan yang ada. Berikut diagram alir Metode Penelitian yang digunakan dapat dilihat pada gambar 2 berikut :

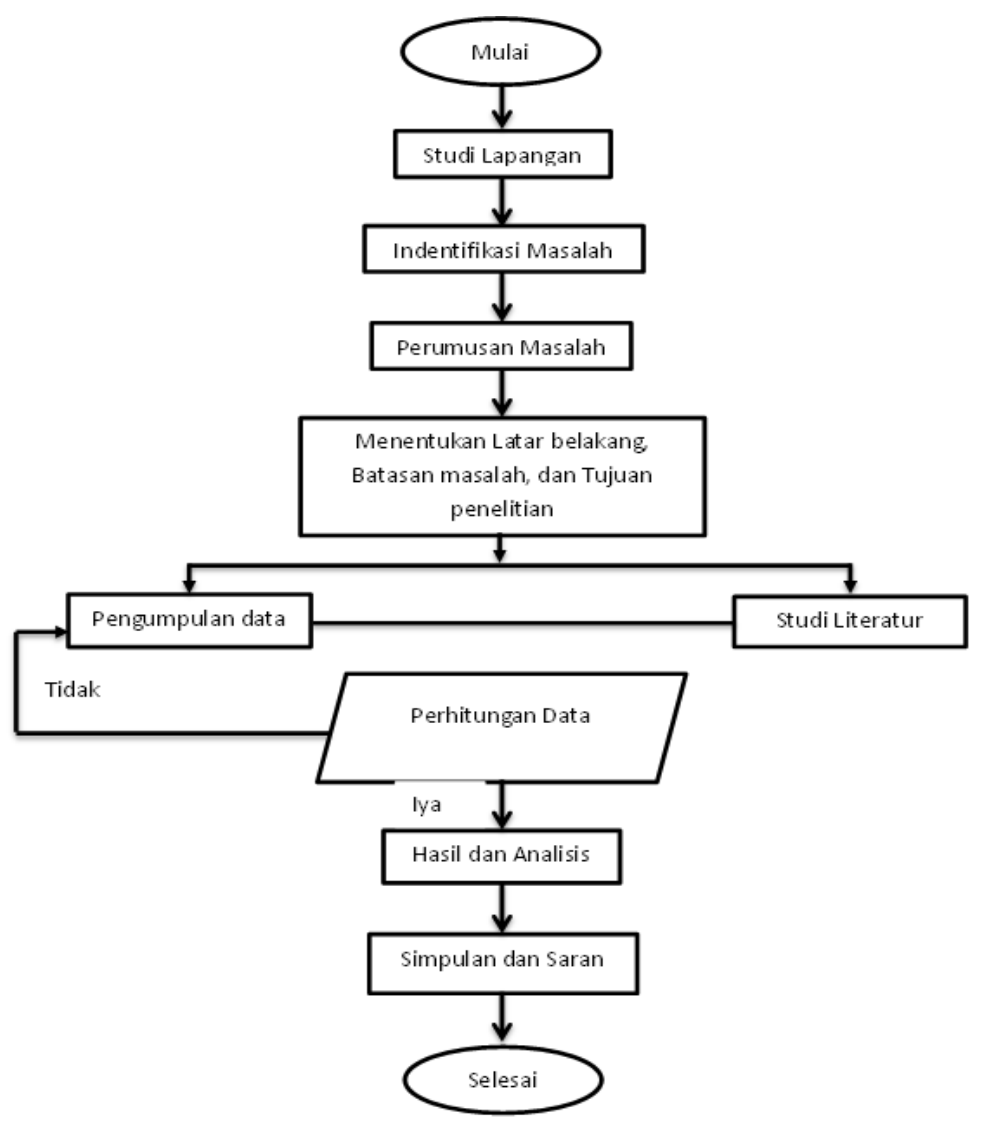

Gambar 2. Diagram Alir Proses Penelitian

\section{Peralatan Percobaan}

Pengambilan data dilakukan menggunakan alat ukut. Alat ukur yang digunakan adalah sebagai berikut Sensor Transmitter, Pembacaan temperatur, tekanan, dan laju alir digunakan sensor transmitter sebagai alat untuk pembacaan parameter turbin uap. Sensor Gauge, Selain menggunakan transmitter pembacaan emperatur dan tekanan digunakan juga sensor gauge sebagai pembanding data yang terbaca oleh transmitter dan data aktual lapangan.

\section{Spesifikasi desain Turbin}

Tabel 1. Spesifikasi Desain Turbin Unit 3

\begin{tabular}{|c|c|}
\hline Lokasi & Turbin Area \\
\hline Pabrik & Ansaldo Copenenti \\
\hline Years & 1992 \\
\hline Type & $\mathrm{SC} 2 \mathrm{~F}$ \\
\hline Rating & $55000 \mathrm{~kW}$ \\
\hline Tekanan uap masuk & $6.5 \mathrm{bar}$ \\
\hline Tekanan uap bekas & $0,102 \mathrm{bar}$ \\
\hline Temperatur & $162^{\prime} \mathrm{C}$ \\
\hline Putaran & $3000 \mathrm{rpm}$ \\
\hline Jumlah tingkat & $6+6$ \\
\hline
\end{tabular}




\section{Spesifikasi desain Kondensor}

Tabel 2. Spesifikasi Desain Kondenser Unit 3

\begin{tabular}{|c|c|}
\hline Lokasi & Condensor Area \\
\hline Internal volume & $527 \mathrm{~m} 3$ \\
\hline Size & $1200 \times 6500 \times 6750 \mathrm{~mm}$ \\
\hline Turbin exhaust Press & $0,107 \mathrm{bar}$ \\
\hline Steam Saturation temp & 47 'C \\
\hline Gas weight content & $1,5 \%$ \\
\hline Cooling water inlet flow & 3271,1 \\
\hline Cooling water inlet temp & $27,6 ' \mathrm{C}$ \\
\hline Hot water outlet temp & $44 ' \mathrm{C}$ \\
\hline Cooling water flow & $2937,2 \mathrm{~kg} / \mathrm{s}$ \\
\hline Type of spray nozzle & Whirl jet \\
\hline
\end{tabular}

\section{Perhitungan Desain}

\section{Heat Rate}

Dengan mengambil salah satu sampel penelitian, maka dilakukan perhitungan sebagai berikut :

$$
T H R=T S R x(h 4)
$$

Sebelum menghitung Turbin Heat Rate, dilakukannya Turbin Steam Rate untuk menghitung nilai konsumsi uap spesifik di peroleh dengan persamaan berikut :

Dimana

$$
T S R=\frac{m\left(\frac{k g}{h}\right)}{W(k W)}
$$

$\mathrm{m}=$ Main steam flow atau uap yang dipakai $(\mathrm{kg} / \mathrm{h})$

$\mathrm{W}=$ Daya output atau daya yang dihasilkan $(\mathrm{kW})$

$$
T S R=\frac{450000\left(\frac{k g}{h}\right)}{60000(k W)}=7,6 \frac{\mathrm{kg}}{\mathrm{kWh}}
$$

Setelah didapatkan nilai TSR maka dilanjutkan perhitungan THR :

$$
\begin{gathered}
\text { THR }=\text { TSR } x(\mathrm{h4}) \\
T H R=7,6 \mathrm{~kg} / \mathrm{Kwh} \times(2.759,595 \mathrm{~kJ} \mathrm{~kg}) \\
T H R=20.973,036 \mathrm{~kJ} / \mathrm{kWh}
\end{gathered}
$$

\section{Efisiensi Kondensor}

Perhitungan ini menggunakan metode output - input :

$$
\begin{gathered}
\eta \text { cond }=\frac{H 2}{H 1+H 3} \times 100 \% \\
2580,675 \frac{\mathrm{kJ}}{\mathrm{kg}} \\
=\frac{\begin{array}{c}
\mathrm{kg} \\
=115,711 \frac{\mathrm{kJ}}{\mathrm{kg}}
\end{array}}{2759,610,75 \%}
\end{gathered}
$$

\section{Kesetimbangan Energi (steady)}

Dimana

$$
\text { Ws. } h 1+\text { Wct. } h 2=\text { Wcond. } h 3
$$

Ws : Laju aliran uap keluar turbin $(\mathrm{kg} / \mathrm{h})$ 
Wc : Laju aliran air pendingin $(\mathrm{kg} / \mathrm{h})$

Wcond : Laju aliran condensate $(\mathrm{kg} / \mathrm{h})$

$\mathrm{h}$ : Entalphy $(\mathrm{kJ} / \mathrm{kg})$

○ $450.000(\mathrm{~kg} / \mathrm{h}) \times 2762,799(\mathrm{~kJ} / \mathrm{kg})+10.573 .920(\mathrm{~kg} / \mathrm{h}) \times 115,711 \mathrm{~kJ} / \mathrm{kg}=26.000 \mathrm{~kg} / \mathrm{h}$ x $2580,675 \mathrm{~kJ} / \mathrm{kg}$

○ $1.243 .259 .550+1.223 .518 .857=67.097 .550$

○ $2.466 .778 .407=67.097 .550$

○ 0,02721

\section{Perhitungan Aktual}

\section{Heat Rate}

Dimana

$$
T S R=\frac{m\left(\frac{k g}{h}\right)}{W(k W)}
$$

$\mathrm{m}=$ Main steam flow atau uap yang dipakai $(\mathrm{kg} / \mathrm{h})$

$\mathrm{W}=$ Daya output atau daya yang dihasilkan $(\mathrm{kW})$

Setelah didapatkan nilai TSR maka dilanjutkan perhitungan THR :

$$
T S R=\frac{437000\left(\frac{\mathrm{kg}}{\mathrm{h}}\right)}{60000(\mathrm{~kW})}=7,2833 \frac{\mathrm{kg}}{\mathrm{kWh}}
$$

$$
T H R=T S R x(h 4)
$$

$$
T H R=7,283 \mathrm{~kg} / \mathrm{kWh} x(2.758,198 \mathrm{~kJ} / \mathrm{kg}) \quad T H R=20.088,783 \mathrm{~kJ} / \mathrm{kWh}
$$

Tabel 3. Hasil Perhitungan Heat Rate 24 Jam

\begin{tabular}{|c|c|c|c|c|c|}
\hline Jam & 00.00 & 01.00 & 02.00 & 03.00 & 04.00 \\
\hline Heat Rate & 20088,87543 & 20182,4104 & 20185,60047 & 20182,4104 & 20142,7878 \\
\hline
\end{tabular}

\begin{tabular}{|c|c|c|c|c|}
\hline 05.00 & 06.00 & 07.00 & 08.00 & 09.00 \\
\hline 20142,7878 & 20135,6411 & 20137,2325 & 20146,7225 & 20146,7225 \\
\hline
\end{tabular}

\begin{tabular}{|c|c|c|c|c|}
\hline 10.00 & 11.00 & 12.00 & 13.00 & 14.00 \\
\hline 20100,72542 & 20198,22172 & 20194,29998 & 20143,5762 & 20089,66932 \\
\hline
\end{tabular}

\begin{tabular}{|c|c|c|c|c|}
\hline 15.00 & 16.00 & 17.00 & 18.00 & 19.00 \\
\hline 20135,6411 & 20135,6411 & 20135,6411 & 20138,8239 & 20141,2037 \\
\hline
\end{tabular}

\begin{tabular}{|c|c|c|c|c|}
\hline 20.00 & 21.00 & 22.00 & 23.00 & 24.00 \\
\hline 20141,9921 & 20187,18818 & 20141,2037 & 20141,9921 & 20187,97838 \\
\hline
\end{tabular}

\section{Efisiensi Kondensor}

Perhitungan ini menggunakan metode output - input.

\begin{tabular}{|c|c|c|c|c|c|c|c|}
\hline $\mathrm{Jam}$ & 00.00 & 01.00 & 02.00 & 03.00 & 04.00 & 05.00 & 06.00 \\
\hline Efisiensi Cond & 82,35 & 82,23 & 82,04 & 82,15 & 82,03 & 82,03 & 82,27 \\
\hline & 07.00 & 08.00 & 09.00 & 10.00 & 11.00 & 12.00 & 13.00 \\
\hline & 82,24 & 82,31 & 82,32 & 82,21 & 82,26 & 82,35 & 82,42 \\
\hline & 14.00 & 15.00 & 16.00 & 17.00 & 18.00 & 19.00 & 20.00 \\
\hline & 82,45 & 82,26 & 82,29 & 82,29 & 82,28 & 82,21 & 82,41 \\
\hline
\end{tabular}

$$
\begin{aligned}
\eta \operatorname{cond}=\frac{H 2}{H 1+H 3} & x 100 \% \\
\eta \text { cond } & =82,35 \%
\end{aligned}
$$

Tabel 4. Perhitungan Efisiensi 24jam

\begin{tabular}{|c|c|c|c|}
\hline 21.00 & 22.00 & 23.00 & 00.00 \\
\hline 82,22 & 82,25 & 82,15 & 82,13 \\
\hline
\end{tabular}




\section{Kesetimbangan Energi}

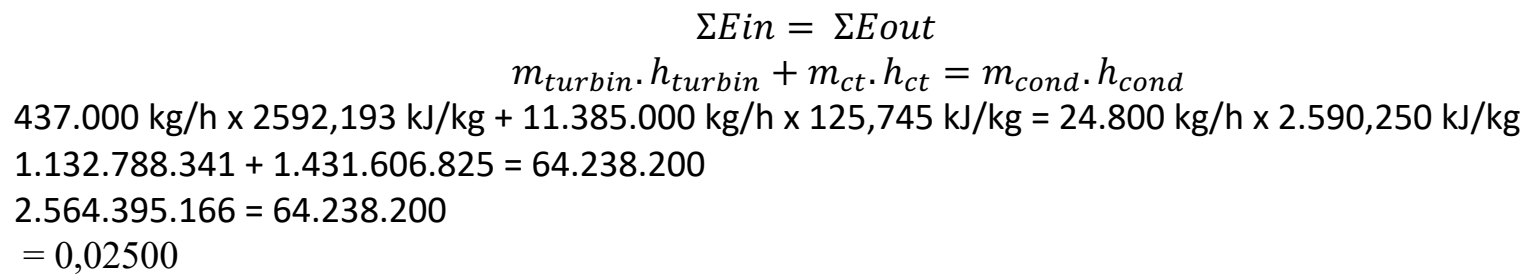

Tabel 5. Perhitungan Kesetimbangan 24jam

\begin{tabular}{|}
$\mid$\begin{tabular}{|c|c|c|c|c|c|c|}
\hline Jam & 00.00 & 01.00 & 02.00 & 03.00 & 04.00 & 05.00 \\
\hline Kesetimbangan energi & 0,0251 & 0,0249 & 0,0245 & 0,0249 & 0,0248 & 0,0253 \\
\hline 06.00 & 07.00 & 08.00 & 09.00 & 10.00 & 11.00 & 12.00 \\
\hline 0,0248 & 0,0249 & 0,0250 & 0,0250 & 0,0250 & 0,0247 & 0,0247 \\
\hline
\end{tabular}
\end{tabular}

\begin{tabular}{|l|l|l|l|l|l|}
\hline 13.00 & 14.00 & 15.00 & 16.00 & 17.00 & 18.00 \\
\hline 0,050 & 0,0260 & 0,0255 & 0,0255 & 0,0255 & 0,0251 \\
\hline
\end{tabular}

\begin{tabular}{|c|c|c|c|c|c|}
\hline 19.00 & 20.00 & 21.00 & 22.00 & 23.00 & 00.00 \\
\hline 0,0246 & 0,0249 & 0,0252 & 0,0245 & 0,0251 & 0,0244 \\
\hline
\end{tabular}

\section{HASIL DAN PEMBAHASAN}

Berdasarkan hasil perhitungan berikut ada lah hasil perbandingan secara desain dengan kondisi secara aktual.

Perbandingan heat rate desain $\&$ aktual

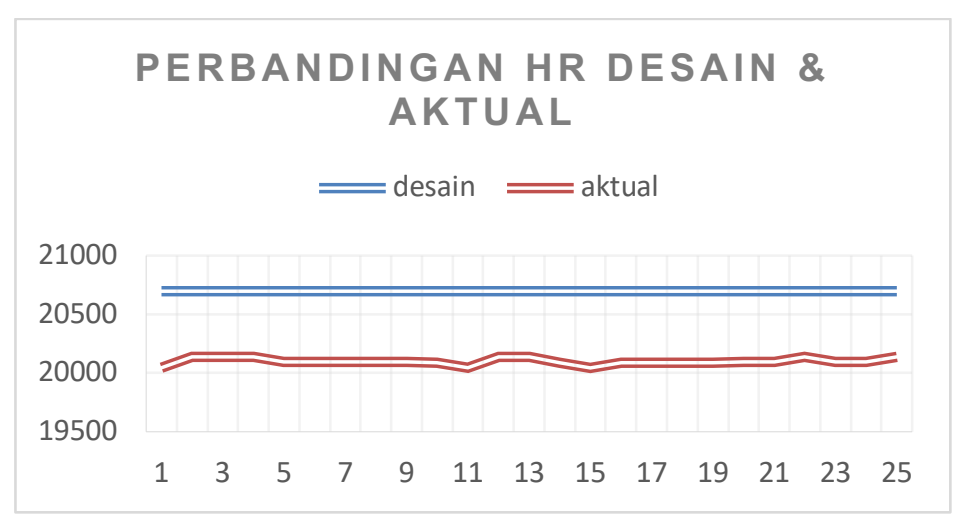

Gambar 3. Grafik Perbandingan HR Desain \& Actual

Dari gambar diatas dapat dilihat bahwa heat rate pada saat kondisi secara aktual mengalami penurunan yang dibandingkan dengan data desain. Heat rate desain yaitu sebesar $20.973,036 \mathrm{~kJ} / \mathrm{kWh}$ sedangkan heat rate pada saat kondisi aktual sebesar $20.088,783 \mathrm{~kJ} / \mathrm{kWh}$ atau mempunyai deviasi sebesar $4,2 \%$. Untuk toleransi dari heat rate sendiri berdasarkan ASME PTC 6 yaitu sebesar 2\%. Jadi untuk heat rate pada saat aktual sudah melebihi dari toleransi yang sudah diberikan.

\section{Perbandingan efisiensi kondensor desain \& aktual}




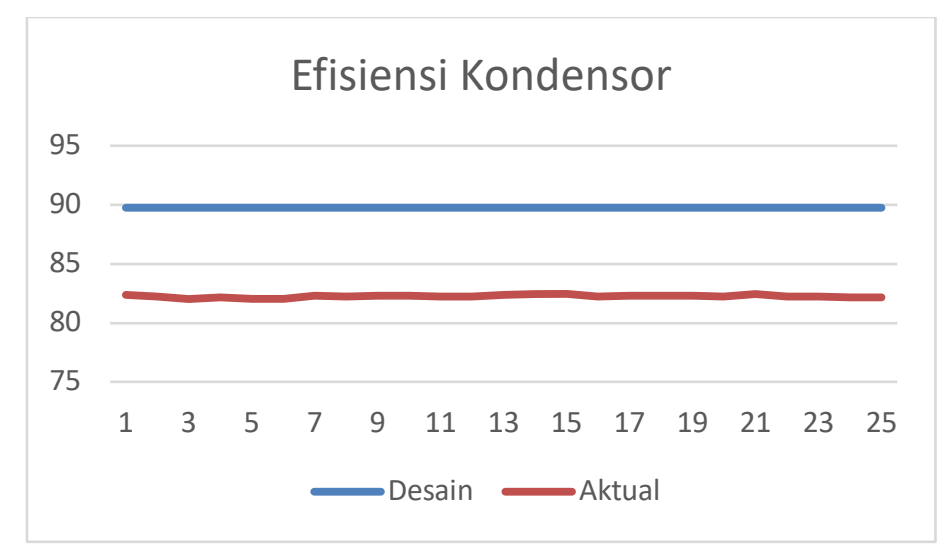

Gambar 4. Grafik Perbandingan Efisiensi Desain \& Aktual

Dari gambar diatas dilihat bahwa efisiensi kondensor pada saat kondisi aktual lebih kecil jika dibandingkan dengan desain. Nilai efisiensi kondensor desain sebesar $89,75 \%$, sedangkan pada kondisi secara aktual yaitu $82,35 \%$. Efisiensi kondensor desain lebih baik kinerjanya karena exhaust press, dan kondisi ruangan vakum lebih baik dibandingkan dengan data aktual.

\section{Kesetimbangan Energi}

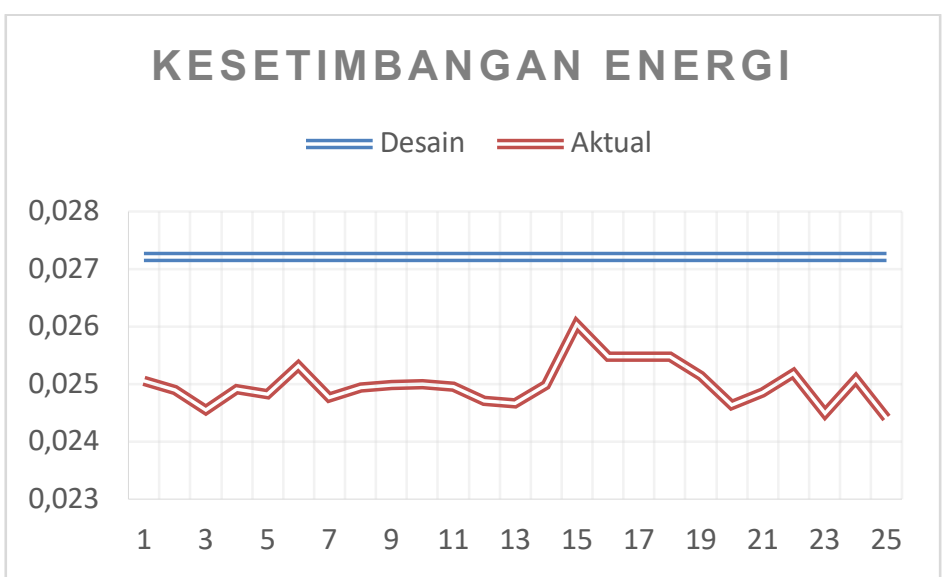

Gambar 5. Grafik Perbandingan Kesetimbangan Energi Desain \& Actual

Dari gambar diatas dilihat bahwa kesetimbangan energi didalam kondensor pada saat kondisi aktual lebih kecil jika dibandingkan dengan desain. Nilai kesetimbangan energi kondensor desain sebesar 0,02721, sedangkan pada kondisi secara aktual yaitu 0,02505 dan memiliki perbedaan 0,00216 . Pada jam 14.00 kinerja pada sistem berjalan sangat baik, namun pada jam 00.00 memiliki nilai paling rendah. Disebabkan karena bocornya isolasi didalam maupun diluar sistem yang mengakibatkan suhu lingkungan dapat mempengaruhi kinerja dari peralatan tersebut.

\section{KESIMPLAN DAN SARAN}

Dari hasil perhitungan dan analisis yang telah dilakukan pada kondensor tipe spray unit 3, maka dapat disimpulkan bahwa :

1) Heat rate pada turbin desain yaitu sebesar $20.696,965 \mathrm{~kJ} / \mathrm{kWh}$ sedangkan heat rate pada saat kondisi aktual sebesar $20.046,144 \mathrm{Kj} / \mathrm{kWh}$ atau mempunyai deviasi sebesar 3,1\%. Untuk toleransi dari heat rate sendiri berdasarkan ASME PTC 6 yaitu sebesar 2\%. Jadi untuk heat rate pada saat aktual sudah melebihi dari toleransi yang sudah diberikan. Semakin besar nilai heat rate maka nilai efisiensi turbin akan turun dan disebabkan nya exhaust pressure maupun temperatur out pada turbin tersebut lebih rendah.

2) Efisiensi kondensor pada saat kondisi aktual lebih kecil jika dibandingkan dengan data desain. Nilai efisiensi kondensor desain sebesar $89,65 \%$, sedangkan pada kondisi secara aktual yaitu $82,35 \%$. Efisiensi kondensor desain lebih karena exhaust press, dan kondisi ruangan vakum lebih baik dibandingkan dengan data aktual. 
3) Kesetimbangan energi didalam kondensor pada saat kondisi aktual lebih kecil jika dibandingkan dengan desain. Nilai kesetimbangan energi kondensor desain sebesar 0,02721, sedangkan pada kondisi secara aktual yaitu 0,02505 dan memiliki perbedaan 0,00216 . Pada jam 14.00 kinerja pada sistem berjalan sangat baik, namun pada jam 00.00 memiliki nilai paling rendah. Disebabkan karena bocornya isolasi didalam maupun diluar sistem yang mengakibatkan suhu lingkungan dapat mempengaruhi kinerja dari peralatan tersebut.

4) Melakukan perawatan/maintenace lebih lanjut terhadap isolasi didalam maupun luar sistem, agar suhu lingkungan tidak mempengaruhi jalannya kinerja dari peralatan tersebut, supaya dapat memaksimalkan kinerja nya dan menjaga kondisi vakum ruangan yang ada di dalam kondensor.

\section{REFERENCES}

Aziz, Amiral. 2011. Analisa Eksergi PLTP Kamojang 68 Kapasitas 3 MW, Jakarta: Peneliti Konversi dan Energi dan Team Panas Bumi BPPT

American Society of Mechanical Engineering. 2006. Erratum to ASME PTC 6-2004 Steam Turbine. New York, USA: ASME

Bambang Teguh P. 2015. Modul BALANCE OF PLANT and HEAT EXCHANGERS IN STEAM POWER PLANT.

Cengel, Boles. 2003. Thermodynamics: An Engineering Approach. USA: John Wiley \& Sons Ltd

DiPippo, Ronald. 2012. Geothermal Power Plants: Principles, Applications, Case Studies and Enviromental. Elsivier

Hall, Carin 2011. Indonesia's Geothermal Potential Being Hamstrung by Regional Polictics. Energy Digital.

Illah, Ibnu Atho. 2016. Analisis Eksergi Sistem Pembangkit Tenaga Panas Bumi Siklus Uap Hasil Pemisahan (Saparated Steam Cycle) di PT Indonesia Power UPJP Kamojang. Skripsi. Jember: Jurusan Energi terbarukan Politeknik Negeri Jember

indarluhsepdyanuri.blogspot.com/2015/06/siklus-uap-kering-direct-dry-steam-cycle.html

Manual Book Vol 1 PLTP PT.X

Moran, M. J., Shapiro, H, N. 2007. Fundamentals of Engineering Thermodinamics, John Wiley\& Sons: New York.

P.K.Nag. 2008. Power Plant Engineering Thrid Edition. New Delhi : Tata McGraw-Hill Publishing Company Limited 